\title{
Information processing and the decremental effect of intermittent reinforcement schedules in human conditioning
}

\author{
WILLIAM F. PROKASY \\ University of Utah, Salt Lake City, Utah 84112 \\ and \\ WILLIAM C. WILLIAMS \\ Eastern Washington University, Cheney, Washington 99004
}

\begin{abstract}
Human conditioning performance decreases as a function of decreases in reinforcement ratio. It was shown that this effect is not exclusively a result of trial-by-trial increments and decrements associated with unconditioned stimulus presence vs. absence. Decreases in reinforcement ratio also increase the number of trials required before CRs emerge and decrease the limit of operators employed to describe performance once acquisition begins. The latter two effects were interpreted to mean, first, that more time is required by subjects to develop the associative network requisite to response acquisition and, second, that information about reinforcement schedules beyond trial-by-trial effects determines overall boundary conditions of performance. The results were discussed from an information processing perspective that differentiates between the acquisition of knowledge about the schedules and the trial-by-trial feedback effects that shape performance.
\end{abstract}

From the perspective of both traditional associative frameworks (e.g., Estes, 1950; Perkins, 1968; Rescorla \& Wagner, 1972; Spence, 1956) and of information processing schemata (e.g., Grant, 1972; Wagner, 1976, 1978), strength theories designed to account for the acquisition and maintenance of a Pavlovian conditioned response (CR) have a common characteristic: Whether the observed response increases or decreases in likelihood on a particular trial depends on that trial's outcome. Specifically, if the unconditioned stimulus (US) occurs, there will be an increment, and if it fails to occur ( $\overline{\mathrm{US}}$ ), there will be a decrement. It is the purpose of this paper to examine the sufficiency of that theoretical proposition in accounting for the decremental effects of intermittent reinforcement schedules in human conditioning.

Two facts are wholly consistent with the incrementaldecremental account: Usually, an intermittent reinforcement schedule results in a lower average level of performance than that observed with a $100 \%$ reinforcement schedule (see, e.g., Gormezano \& Moore, 1969, p. 166) and, in the human literature, there is clear evidence of an average decremental effect following nonreinforced trials (Higgins \& Prokasy, 1968; Prokasy,

This research was supported by NSF Grant BNS-75-10471 and PHS Grant MH-31606 to the senior author and by NIH Biomedical Research Support Grant RR07092 to the University of Utah. We would like to acknowledge the technical aid provided by Craig C. Clark, Karol L. Kumpfer, and William Yu-Ming Lee.
Carlton, \& Higgins, 1967; Prokasy, Higgins, \& Carlton, 1968). It is to be noted, however, that not in all instances (Gormezano \& Moore, 1969, p. 166) is there an overall reduced level of performance. In addition, when there is an overall reduced level of performance, the effect is not necessarily attributable to trial-by-trial decremental effects of US omission (Prokasy \& Gormezano, 1979).

There are two additional considerations. The first is that performance is affected by the nature of the reinforcement schedule beyond the trial-specific consequences of US presence vs. absence. For example, Prokasy, Carlton, and Higgins (1967) have shown that a subset of human subjects exposed to a doublealternation schedule tend to respond on US trials and not respond on $\overline{\mathrm{US}}$ trials, thus reflecting a discrimination of the double-alternation sequence. In addition, if an intermittent reinforcement schedule is biased toward runs of reinforced trials or runs of nonreinforced trials, response likelihood, respectively, increases and decreases more rapidly than if the run bias were not present (Higgins \& Prokasy, 1968; Prokasy, Carlton, \& Higgins, 1967; Prokasy \& Kumpfer, 1969). Thus, discriminable contingencies in trial sequencing affect performance beyond the influence of trial-by-trial outcomes. We do not know, however, whether information about a random schedule (e.g., ratio of reinforcement) has an impact on performance.

The second consideration is that reducing the reinforcement ratio may have its major impact prior 
to the emergence of CRs. Specifically, Prokasy and Gormezano (1979) have shown that the emergence of conditioned nictitating membrane responses in rabbits is delayed when the reinforcement percentage is reduced from $100 \%$ to $50 \%$. Once CRs emerged, however, there was little evidence of the trial-by-trial increments and decrements that would be expected following, respectively, US and $\overline{\text { US }}$ trials. This particular outcome makes it quite clear that the incremental-decremental account is not a sufficient account of the impact at intermittent reinforcement schedules across species.

The effects of an intermittent reinforcement schedule may appear in one or more of three different ways: the number of trials required before $\mathrm{CR}$ emergence is detected; the overall parameters, or boundary conditions, for performance; and trial-by-trial incrementaldecremental effects of US and $\overline{U S}$. These can be identified more clearly from the framework of the two-phase model of conditioning (Prokasy, 1972; Prokasy \& Harsanyi, 1968). The model is two-phase in the sense that during Phase 1 responses occur at a base rate, $\mathrm{P}_{\mathrm{o}}$, for some number of trials, $\mathrm{K}$, and that during Phase 2 CR likelihood changes and acquisition takes place. Response probability on Trial $i, P_{i}$, is expressed as: (1) $P_{i}=P_{0}, i \leqslant K$; (2) $P_{i}=P_{i-1}+\theta_{1}\left(\lambda_{1}-\right.$ $\left.P_{i-1}\right), i>K$, given CR, US on Trial $i-1 ;(3) P_{i}=P_{i-1}+$ $\theta_{2}\left(\lambda_{2}-\mathrm{P}_{\mathrm{i}-1}\right), \mathrm{i}>\mathrm{K}$, given $\overline{\mathrm{CR}}$, US on Trial $\mathrm{i}-1$; (4) $P_{i}=P_{i-1}+\theta_{3}\left(\lambda_{3}-P_{i-1}\right), i>K$, given $C R$, US on Trial $\mathrm{i}-1$; (5) $\mathrm{P}_{\mathrm{i}}=\mathrm{P}_{\mathrm{i}-1}+\theta_{4}\left(\lambda_{4}-\mathrm{P}_{\mathrm{i}-1}\right), \mathrm{i}>\mathrm{K}$, given $\overline{\mathrm{CR}}, \overline{\mathrm{US}}$ on Trial $\mathrm{i}-1$, where $\theta \mathrm{s}$ are rates of change and $\lambda s$ are operator limits. Note that there is a separate Phase 2 operator for each possible trial outcome.

The study to be reported manipulated reinforcement ratio in a human eyelid response conditioning situation. Of particular interest is the number of trials required to transfer from Phase 1 to Phase 2 (the parameter K), the operator parameters for Phase 2 (i.e., $\theta$ and $\lambda$ ), and whether or not distinct operators are required to differentiate US and $\overline{\mathrm{US}}$ trials. These indices correspond to the three kinds of impact that an intermittent reinforcement schedule can have on performance.

\section{METHOD}

\section{Subjects}

The subjects were 101 volunteers from introductory psychology classes at the University of Utah.

\section{Apparatus}

The apparatus details are described elsewhere (Prokasy, Clark, Williams, \& Spurr, 1975) and will not be repeated here. The CS was a 500-msec brightness change of a milk-glass disk located at eye level approximately $1 \mathrm{~m}$ in front of the subject. The US was a 50-msec puff of nitrogen, sufficient to support a $150-\mathrm{mm}$ column of mercury, directed at the subject's right cornea from a distance of approximately $2 \mathrm{~cm}$.

Eyelid movements of at least 1 -mm amplitude occurring within the range of $152-158 \mathrm{msec}$ after CS onset were defined as CRs. Recording was done via a piano wire attached to the subject's eyelid and to the shaft of a microtorque potentiometer with the signal amplified and recorded with a Beckman Type $\mathrm{R}$ dynograph. All event programming was controlled via a PDP-12/A computer.

\section{Design and Procedure}

Four groups of subjects were employed. A minimum of 25 subjects was assigned to each group, and all experienced the CS and US paired with an interstimulus interval of $500 \mathrm{msec}$. The proportion of reinforced trials varied across groups, the ratios being $.25, .50, .75$, and 1.0 for groups labeled 25,50 , 75 , and 100 , respectively.

Two subjects were run simultaneously whenever possible. When the subjects arrived at the laboratory, they signed the log and were seated at desks in the experimental rooms. After the transducer was attached, tape-recorded instructions of the "just let your reactions take care of themselves" variety were given. The subjects then received 49 adaptation trials consisting of 24 CSs and 25 USs presented in an unsystematic order using a mean intertrial interval of $9 \mathrm{sec}$ (the range was from 6 to $12 \mathrm{sec}$ ) followed by 240 conditioning trials using an intertrial interval of $10.5 \mathrm{sec}$ (ranging from 6 to $15 \mathrm{sec}$ ).

\section{RESULTS}

Mean terminal response probability for Groups 25, 70,75 , and 100 over the last 60 trials was, respectively, $.296, .551, .601$, and .762 . The differences, in a test conducted across all trials, were statistically significant $[F(3,97)=10.70]$.

Parameters for the two-phase model were estimated separately for each subject with procedures described in detail elsewhere (Prokasy, 1973). $P_{o}$ was estimated from response probability during the adaptation trials, and the remaining parameters were estimated with the subroutine STEPIT (Chandler, 1969). The methods employed (see Prokasy \& Gormezano, 1979, for details) permitted us to categorize each subject into one of four Phase 2 assumption categories: (A) $\lambda_{1}=\lambda_{2}=\lambda_{3}=\lambda_{4}$; (B) $\lambda_{1}=\lambda_{2} \neq \lambda_{3}=\lambda_{4}$;(C) $\lambda_{1}=\lambda_{3} \neq \lambda_{2}=\lambda_{4}$;(D) $\lambda_{1} \neq$ $\lambda_{2} \neq \lambda_{2} \neq \lambda_{3} \neq \lambda_{4}$. Each of the assumption categories has different implications for Trial $n$ based on the outcome of Trial $n-1$. Differential effects of $C R$ presence vs. absence are implied in Assumptions $\mathrm{C}$ and $D$, while differential effects of US presence vs. absence are implied in Assumptions B and D. Assumption A implies no differential trial-by-trial effects of either the CR or the US dimension. It was assumed, finally, that there were no within-subjects differences in values of $\theta$ (see Prokasy \& Gormezano, 1979, for rationale).

Mean parameter estimates were calculated separately for the subjects falling in the different assumption categories (Table 1). Although values of $P_{o}$ varied substantially across groups, they did not differ significantly. Table 1 makes it quite clear that the reinforcement schedules do not affect all subjects in the same way within any given treatment level. Of particular interest is that most subjects in Groups 25, 50, and 75 exhibited no differential aftereffects of US presence vs. absence (Assumptions A and C). A sizable minority (Assumption A) exhibited no differential effects on Trial $n$ of either CR presence vs. absence or US presence vs. absence on Trial $n-1$. 
Table 1

Mean Parameter Estimates for Assumption Categories Within Groups

\begin{tabular}{|c|c|c|c|c|c|c|c|}
\hline Group & & $\begin{array}{c}\text { Assump- } \\
\text { tion }\end{array}$ & $\mathrm{n}$ & $\lambda_{1}$ & $\lambda_{2}$ & $\lambda_{3}$ & $\lambda_{4}$ \\
\hline R100 & $\begin{array}{l}P_{\mathrm{o}}=.102 \\
\mathrm{~K}=16.9 \\
\theta=.391\end{array}$ & $\begin{array}{l}\mathrm{A} \\
\mathrm{C}\end{array}$ & $\begin{array}{r}17 \\
8\end{array}$ & $\begin{array}{l}.844 \\
.825\end{array}$ & $\begin{array}{l}.844 \\
.329\end{array}$ & $\begin{array}{l}.844 \\
.825\end{array}$ & $\begin{array}{l}.844 \\
.329\end{array}$ \\
\hline R75 & $\begin{array}{l}\mathrm{P}_{\mathrm{O}}=.142 \\
\mathrm{~K}=36.8 \\
\theta=.482\end{array}$ & $\begin{array}{l}\text { A } \\
\text { B } \\
\text { C } \\
\text { D }\end{array}$ & $\begin{array}{r}10 \\
6 \\
5 \\
4\end{array}$ & $\begin{array}{l}.687 \\
.748 \\
.782 \\
.661\end{array}$ & $\begin{array}{l}.687 \\
.748 \\
.162 \\
.384\end{array}$ & $\begin{array}{l}.687 \\
.339 \\
.782 \\
.296\end{array}$ & $\begin{array}{l}.687 \\
.339 \\
.162 \\
.344\end{array}$ \\
\hline R50 & $\begin{array}{l}\mathrm{P}_{\mathrm{O}}=.200 \\
\mathrm{~K}=47.4 \\
\theta=.389\end{array}$ & $\begin{array}{l}\text { A } \\
\text { B } \\
\text { C } \\
\text { D }\end{array}$ & $\begin{array}{r}8 \\
10 \\
3 \\
4\end{array}$ & $\begin{array}{l}.709 \\
.747 \\
.513 \\
.725\end{array}$ & $\begin{array}{l}.709 \\
.747 \\
.278 \\
.681\end{array}$ & $\begin{array}{l}.709 \\
.236 \\
.513 \\
.232\end{array}$ & $\begin{array}{l}.709 \\
.236 \\
.278 \\
.091\end{array}$ \\
\hline $\mathrm{R} 25^{*}$ & $\begin{array}{l}\mathrm{P}_{\mathrm{o}}=.112 \\
\mathrm{~K}=75.0 \\
\theta=.521\end{array}$ & $\begin{array}{l}\text { A } \\
\text { B } \\
\text { C } \\
\text { D }\end{array}$ & $\begin{array}{r}16 \\
3 \\
3 \\
1\end{array}$ & $\begin{array}{l}.281 \\
.740 \\
.639 \\
.404\end{array}$ & $\begin{array}{l}.281 \\
.740 \\
.294 \\
.000\end{array}$ & $\begin{array}{l}.281 \\
.287 \\
.639 \\
.000\end{array}$ & $\begin{array}{l}.281 \\
.287 \\
.294 \\
.732\end{array}$ \\
\hline
\end{tabular}

*Data of three subjects were excluded since $K$ exceeded 200 , thus making Phase 2 parameter estimates unreliable.

Table 1 shows that 10,14 , and 4 subjects exhibited differential aftereffects of US presence vs. absence. Of these, all but two had lower $\lambda$ s for the US operator. The only other systematic effect of the reinforcement schedule was the reduction in $\lambda$ for Assumption A subjects as reinforcement ratio decreased $[F(3,47)=10.20]$.

Although not germane to issues raised in the introduction, it should be noted that of the 19 subjects classified under Assumption C, 18 had lower limits for $\overline{\mathrm{CR}}$ trials than for CR trials $\left[\chi^{2}(1)=15.21\right]$.

\section{DISCUSSION}

The basic problem for this study was to determine whether or not strength interpretations of Pavlovian conditioning are sufficient to account for the influence of random intermittent reinforcement schedules in human eyelid response conditioning. This would be demonstrated in its most extreme form by accounting entirely for the decremental effects of US omission by Phase 2 operators applied differentially to US and $\overline{U S}$ trials. That this is an insufficient account is evident in two ways: Only a subset of subjects exhibited decrements in response probability following US trials, and parameters other than those directly associated with $\overline{\mathrm{US}}$ omission were influenced by reinforcement ratio.

A useful perspective from which to interpret the results is that of information processing (e.g., Bower, 1975; Grant, 1972; Shiffrin, 1976; Wagner, 1978). Early in training (i.e., Phase 1), the organism gains knowledge about the environment, in this case including the CS-US relationship, features of the reinforcement schedule, and characteristics of the CS and US. This information is stored in long-term memory or working memory, as distinct from short-term memory. Then a response system is either organized or sought out from an available repertoire and boundary conditions for acquisition are established. Boundary conditions are overall parameters such as $\lambda$ and $\theta$. The establishment of the associative structure, identification (or organization) of a response, and setting of boundary conditions take place during, perhaps define, Phase 1 of the two-phase model. That Phase 1 increases in duration with a reduction of reinforcement ratio reflects, at the very least, the greater difficulty in identifying a relationship between CS and US and in organizing information about the reinforcement schedule. This particular outcome is common to rabbit (Prokasy \& Gormezano, 1979) and human.

Phase 2, during which response likelihood, topography, and latency modify to reflect acquisition, is basically the output phase. Consistent with Grant's (1972, pp. 39-41) view, it constitutes a phase in which a response template is refined. Such a development will depend in part on feedback from each trial's outcome. When a CS is presented, it is represented in short-term memory and recalls from working memory aspects of the environmental contingencies. In Grant's language, a response command may be elicited and the efficiency with which the output stage is organized will determine whether or not a response will occur and the extent to which it is finely tuned to situational constraints.

There are several ways to view the decremental effect that US omission has on some subjects. It could be, for example, the consequence of a weakened representation of the US in working, or long-term, memory (see, e.g., Wagner, 1978). It could also be that US omission in some way makes the response representation less efficient. A third alternative, one that is currently being given experimental scrutiny, is that some subjects, upon CS presentation, have available in short-term memory the outcome of the last trial. Having available information about a preceding $\overline{\mathrm{US}}$ trial may reduce the likelihood of a response command being elicited. Those subjects not exhibiting response decrements following $\overline{\mathrm{US}}$ trials may be recalling from working memory contextual information with no retention in short-term memory of the last trial's outcome. This is a plausible alternative for consideration, since Wagner and his associates (Wagner, 1978) have shown that there are marked short-term memory effects in rabbits lasting up to about $15 \mathrm{sec}$, while Prokasy and Gormezano (1979) obtained only trivial effects of $\overline{\mathrm{US}}$ trials in the same kind of rabbit preparation with intertrial intervals averaging $1 \mathrm{~min}$ or more.

The need for $\mathrm{CR}$ vs. $\overline{\mathrm{C}} \overline{\mathrm{R}}$ operators is apparent from past research on several species (e.g., Prokasy, 1973, 1974; Prokasy, Williams, Lee, \& Kumpfer, 1974). Prokasy and Gormezano (1979) concluded that these operators more likely reflect state changes on the part of the subjects. That is, for some subjects there are spans of trials over which the likelihood of a response is reduced. Whether this constitutes a failure to retrieve contextual information from working memory or, even though there is retrieval, a reduced likelihood of a response command remains to be seen.

\section{REFERENCES}

Bower, G. H. Cognitive psychology: An introduction. In W. K. Estes (Ed.), Handbook of learning and cognitive processes (Vol. 1). Hillsdale, N.J: Erlbaum, 1975.

Chandle R, J. P. STEPIT: Finds local minima of a smooth function of several parameters. Behavioral Science, 1969, 14, 81-82.

Estes, W. K. Toward a statistical theory of learning. Psychological Review, 1950, 57, 94-107.

Gormezano, I., \& Moore, J. W. Classical conditioning. In M. H. Marx (Ed.), Learning: Processes. Toronto: MacMillan, 1969.

Grant, D. A. A preliminary model for processing information conveyed by verbal conditioned stimuli in classical conditioning. In A. H. Black \& W. F. Prokasy (Eds.), Classical conditioning II. New York: Appleton-Century-Crofts, 1972.

Higgins, J. D., \& Prokasy, W. F. The effects of transition probability of reinforcement in intermittent reinforcement schedules in human eyelid conditioning. Psychonomic Science, $1968,12,69-70$. 
Perkins, C. C., JR. An analysis of the concept of reinforcement. Psychological Review, 1968, 75, 155-172.

Prokasy, W. F. Developments with the two-phase model applied to human eyelid conditioning. In A. H. Black \& W. F. Prokasy (Eds.), Classical conditioning II. New York: Appleton-CenturyCrofts, 1972.

Prokasy, W. F. A two-phase model account of aversive classical conditioning performance in humans and rabbits. Learning and Motivation, 1973, 4, 247-258.

Prokasy, W. F. Discriminated avoidance vs classical conditioning: A two-phase model analysis. Animal Learning \& Behavior, 1974, 2, 257-261.

Prokasy, W. F., Carlton, R. A., \& Higgins, J. D. Effects of nonrandom intermittent reinforcement schedules in human eyelid conditioning. Journal of Experimental Psychology, 1967, 74, 282-288.

Prokasy, W. F., Clark, C. G., Williams, W. C., \& Spurr, C. W. Conditioned response-contingent delays of the unconditioned stimulus in human aversive conditioning. Journal of Experimental Psychology: Human Learning and Memory, 1975, 1, 513-520.

Prokasy, W. F., \& Gormezano, I. The effect of US omission in classical aversive and appetitive conditioning of rabbits. Animal Learning \& Behavior, 1979, 7, 80-88.

Prokasy, W. F., \& Harsanyi, M. A. Two-phase model for human classical conditioning. Journal of Experimental Psychology, 1968, 78, 359-368.

Prokasy, W. F., Higgins, J. D., \& Carlton, R. A. Sequential effects in differential human eyelid conditioning. Psychonomic Science, 1968, 12, 58.
Prokasy, W. F., \& Kumpfe R, K. L. Conditional probability of reinforcement and sequential behavior in human conditioning with intermittent reinforcement schedules. Psychonomic Science, $1969,14,49-50$.

Prokasy, W. F., Williams, W. C., Lee, W. Y-M., \& Kumpfer, K. L. Two-phase model analysis of the effects of interstimulus interval and masking task in human aversive classical conditioning. Memory \& Cognition, 1974, 2, 206-210.

Rescorla, R. A., \& Wagner, A. R. A theory of Pavlovian conditioning: Variations in the effectiveness of reinforcement and nonreinforcement. In A. H. Black \& W. F. Prokasy (Eds.), Classical conditioning II. New York: Appleton-Century-Crofts, 1972.

Shiffrin, R. M. Capacity limitations in information processing, attention, and memory. In W. K. Estes (Ed.), Handbook of learning and cognitive processes (Vol. 4). Hillsdale, N.J: Erlbaum, 1976.

Spence, K. W. Behavior theory and conditioning. New Haven: Yale Univeristy Press, 1956.

Wagner, A. R. Priming in STM: An information processing mechanism for self-generated or retrieval-generated depression in performance. In T. J. Tighe \& R. N. Leaton (Eds.), Habituation: Perspectives from child development, animal behavior, and neurophysiology. Hillsdale, N.J: Erlbaum, 1976.

WAGNer, A. R. Expectancies and the priming of STM. In S. H. Hulse, H. Fowler, \& W. K. Honig (Eds.), Cognitive processes in animal behavior. Hillsdale, N.J: Erlbaum, 1978.

(Received for publication April 11, 1979.) 